Perspiration Research 


\section{Current Problems in Dermatology}

Vol. 51

Series Editors

Peter Itin Basel

Gregor B.E. Jemec Roskilde 


\section{Perspiration Research}

Volume Editors

Hiroo Yokozeki Tokyo

Hiroyuki Murota Osaka

Ichiro Katayama osaka

61 figures, 41 in color, and 10 tables, 2016 


\section{Current Problems in Dermatology}

\section{Hiroo Yokozeki}

Department of Dermatology

Graduate School of Medical and Dental Sciences

Tokyo Medical and Dental University

1-5-45 Yushima, Bunkyo-ku

Tokyo 113-8519 (Japan)

\section{Hiroyuki Murota}

Department of Dermatology

Course of Integrated Medicine

Graduate School of Medicine

Osaka University

2-2 Yamadaoka, Suita-shi

Osaka 565-0871 (Japan)

\section{Ichiro Katayama}

Department of Dermatology

Course of Integrated Medicine

Graduate School of Medicine

Osaka University

2-2 Yamadaoka, Suita-shi

Osaka 565-0871 (Japan)

Library of Congress Cataloging-in-Publication Data

Names: Yokozeki, Hiroo, editor. | Murota, Hiroyuki, editor. | Katayama,

Ichiro, editor.

Title: Perspiration research / volume editors, Hiroo Yokozeki, Hiroyuki

Murota, Ichiro Katayama.

Other titles: Current problems in dermatology ; $51.1421-5721$

Description: Basel ; New York : Karger, [2016] | Series: Current problems in

dermatology, ISSN 1421-5721; vol. 51 | Includes bibliographical

references and index.

Identifiers: LCCN 2016030383| ISBN 9783318059045 (hard cover : alk. paper) |

ISBN 9783318059052 (elSBN)

Subjects: | MESH: Sweating--physiology | Sweat Gland Diseases

Classification: LCC RL141 | NLM WR 102 | DDC 616.5/60072--dc23 LC record available at https://lccn.loc.gov/2016030383

Bibliographic Indices. This publication is listed in bibliographic services, including Current Contents ${ }^{\circledR}$ and Index Medicus.

Disclaimer. The statements, opinions and data contained in this publication are solely those of the individual authors and contributors and not of the publisher and the editor(s). The appearance of advertisements in the book is not a warranty, endorsement, or approval of the products or services advertised or of their effectiveness, quality or safety. The publisher and the editor(s) disclaim responsibility for any injury to persons or property resulting from any ideas, methods, instructions or products referred to in the content or advertisements.

Drug Dosage. The authors and the publisher have exerted every effort to ensure that drug selection and dosage set forth in this text are in accord with current recommendations and practice at the time of publication. However, in view of ongoing research, changes in government regulations, and the constant flow of information relating to drug therapy and drug reactions, the reader is urged to check the package insert for each drug for any change in indications and dosage and for added warnings and precautions. This is particularly important when the recommended agent is a new and/or infrequently employed drug.

All rights reserved. No part of this publication may be translated into other languages, reproduced or utilized in any form or by any means electronic or mechanical, including photocopying, recording, microcopying, or by any information storage and retrieval system, without permission in writing from the publisher.

(c) Copyright 2016 by S. Karger AG, P.O. Box, CH-4009 Basel (Switzerland)

www.karger.com

Printed on acid-free and non-aging paper (ISO 9706)

ISSN 1421-5721

e-ISSN 1662-2944

ISBN 978-3-318-05904-5

e-ISBN 978-3-318-05905-2 


\section{Contents}

VII Preface

Yokozeki, H. (Tokyo); Murota, H. (Osaka); Katayama, I. (Osaka)

1 New Pathologies of Skin Disorders Identified from the History of Perspiration Research Yokozeki, H. (Tokyo)

7 Classification of Systemic and Localized Sweating Disorders

Ohshima, Y.; Tamada, Y. (Nagakute)

11 New Findings on the Mechanism of Perspiration Including Aquaporin-5 Water Channel Inoue, R. (Tokyo)

22 Old and New Approaches for Assessing Sweating Murota, H. (Osaka)

30 Sweat as an Efficient Natural Moisturizer

Shiohara, T.; Sato, Y.; Komatsu, Y.; Ushigome, Y.; Mizukawa, Y. (Tokyo)

42 Genetic Disorders with Dyshidrosis: Ectodermal Dysplasia, Incontinentia Pigmenti, Fabry Disease, and Congenital Insensitivity to Pain with Anhidrosis Wataya-Kaneda, M. (Osaka)

50 Histamine Modulates Sweating and Affects Clinical Manifestations of Atopic Dermatitis Takahashi, A.; Tani, S.; Murota, H.; Katayama, I. (Osaka)

57 Sweating in Systemic Abnormalities: Uremia and Diabetes Mellitus Murota, H. (Osaka)

62 Abberant Sudomotor Functions in Sjögren's Syndrome: Comparable Study with Atopic Dermatitis on Dry Skin Manifestation Katayama, I. (Osaka)

75 Clinical Analysis and Management of Acquired Idiopathic Generalized Anhidrosis Satoh, T. (Tokorozawa)

80 Dyshidrotic Eczema and Its Relationship to Metal Allergy Nishizawa, A. (Tokorozawa) 
86 Pathophysiology and Treatment of Hyperhidrosis

Fujimoto, T. (Tokyo)

94 New Etiology of Cholinergic Urticaria

Tokura, Y. (Hamamatsu)

101 Sweat Allergy

Hiragun, T.; Hide, M. (Hiroshima)

109 Perspiration Functions in Different Ethnic, Age, and Sex Populations:

Modification of Sudomotor Function

Lee, J.-B.; Kim, J.-H. (Cheonan); Murota, H.; (Osaka)

120 Author Index

121 Subject Index

(0) 


\section{Preface}

Many investigators worldwide, particularly those in Japan, have performed leading studies on perspiration. In this book, I provide a history of studies on the physiology of perspiration and other research on perspiration. Particularly, I introduce in detail two historical physiologists: Dr. Yasu Kuno, a former professor at Nagoya University who dramatically revealed the physiology of perspiration in the early and maturation stages, and Dr. Kenzo Sato, a former professor at the University of Iowa. These Japanese investigators have played major roles in perspiration research.

Perspiration research developed dramatically in the 2000s. It has since been elucidated that perspiration not only has a temperature-regulating function and a non-slip function for the hands and feet, but also a natural bactericidal function through dermcidin, an antimicrobial peptide contained in sweat. Moreover, we propose that obstruction of the sweat glands plays a major role in the onset of disorders such as parapsoriasis, lichen planus, and lichen amyloidosis, and that Malassezia is an allergen in sweat that exacerbates atopic dermatitis and cholinergic urticaria, making perspiration abnormalities possible causes of many allergic skin disorders. Furthermore, sweat glands were found to play numerous roles, including as storage of stem cells for replenishing epidermal cells in the case of thermal burns and as water retention sites for replenishing moisture in the stratum corneum. We also introduce an analysis of the 3-dimensional structures of the sweat glands in disorders such as dyshidrosis by using high-speed en-face optical coherence tomography (OCT), which can visualize the sweat glands dynamically and 3-dimensionally. OCT provides 3-dimensional imaging by using optical interference; it visualizes the structures of biological tissues under the epidermis at a high resolution and can display the structure of the sweat ducts in the stratum corneum and the epidermis. Furthermore, we demonstrate that sweat and the sweat glands can be visualized by using 2-photon excitation fluorescence microscopy in mice. These 3-dimensional analyses of the sweat glands are likely to unravel novel pathologies of skin disorders in the near future. I hope everyone who reads this book will develop more interest in investigations on perspiration.

Hiroo Yokozeki, Tokyo Hiroyuki Murota, Osaka Ichiro Katayama, Osaka 
